\title{
Studies on the formation and synthetic mechanism of related substance $G$ in potassium clavulanate production
}

\author{
Xiaoqing Jin ${ }^{1}$, Guangxiang Cao ${ }^{1,2}$, Xiaoxiao Zhang', Yuguo Chen ${ }^{1}$, Liang Wang ${ }^{1}$, \\ Chuanqing Zhong,*
}

\author{
${ }^{1}$ National Engineering Research Center of Chiral Drugs, Lunan Pharmaceutical Group Corporation, LinYi, China, \\ ${ }^{2}$ Shandong Academy of Medical Sciences, Ji'nan, Shandong, China, ${ }^{3}$ School of Municipal and \\ Environmental Engineering of Shandong Jianzhu University, Jinan, China
}

\begin{abstract}
The objective of this study was to investigate the formation and synthetic mechanism of related substance $\mathrm{G}$ in potassium clavulanate production. The impurity in the potassium clavulanate final product, with a retention time of $13.5 \mathrm{~min}$, was confirmed as related substance $\mathrm{G}$ by high performance liquid chromatography-mass spectrometry/mass spectrometry. Related substance G analysis during the production of clavulanic acid showed that this impurity could be synthesized during fermentation, and the amount increased with the fermentation time. Studies on its synthetic mechanism showed that L-tyrosine and succinic acid were the precursors for biosynthesis of related substance $\mathrm{G}$ in vivo. The reaction was deduced to be catalyzed by an enzyme. The enzyme was a type of extracellular enzyme present in the fermentation supernatant.
\end{abstract}

Uniterms: Potassium clavulanate/production. Clavulanic acid/production. Related substance G./structure identification. Related substance G./synthetic mechanism. High Performance Liquid ChromatographyMass Spectrometry-Mass Spectrometry/analysis

O objetivo deste estudo foi investigar a formação e o mecanismo sintético da substância G relacionada na produção de clavulanato de potássio. A impureza do produto final clavulanato de potássio, com tempo de retenção de 13,5 min, foi confirmada como substância $G$ relacionada por cromatografia líquida de alta eficiência-espectrometria de massas/espectrometria de massas. A análise da substância G relacionada durante a produção do ácido clavulânico mostrou que essa impureza poderia ser sintetizada durante a fermentação e que a quantidade aumenta com o tempo de fermentação. Estudos do seu mecanismo sintético mostraram que a L-tirosina e o ácido succínico foram os precursores in vivo para a biossíntese da substância G relacionada. Deduziu-se que a reação foi catalisada por uma enzima. A enzima foi do tipo extracelular, presente no sobrenadante da fermentação.

Unitermos: Clavulanato de potássio/produção. Ácido clavulânico/produção. Substância G relacionada/ identificação estrutural. Substância G relacionada/mecanismo sintético. Cromatografia Líquida de Alta Eficiência-Espectrometria de massas-Espectrometria de massas/análise

\section{INTRODUCTION}

As the emergence of antibiotic resistant organisms threatens to return treatment of infectious diseases to a pre-antibiotic era, strategies aimed at overcoming acquired resistance are of increasing interest. One of

\footnotetext{
*Correspondence: Chuanqing Zhong. School of Municipal and Environmental Engineering, Shandong Jianzhu University, Ji’nan, 250101, China. E-mail: newtime2012@sina.com
}

the best examples of wide clinical application of this strategy is the development of $\beta$-lactamase inhibitors for use in combination with conventional $\beta$-lactam antibiotics. Commercial products such as Augmentin ${ }^{\mathrm{TM}}$ and Timentin ${ }^{\mathrm{TM}}$, combinations of clavulanic acid together with amoxicillin or ticarcillin, respectively, have made clavulanic acid a valued product in excess of a billion dollars/annum (Aharonowitz, Demain, 1978; Parag, Shrikant, Rekha, 2008). Clavulanic acid, a type of lactamase inhibitor, is a secondary metabolite produced 
by Streptomyces clavuligerus (Saudagar, Singhal, 2007; Shetty et al., 2010). Potassium clavulanate is the most widely used pharmaceutically acceptable form of clavulanic acid. Usually, potassium clavulanate is produced by industrial fermentation, including three main processes: fermentation, filtration and extraction and crystallization to obtain the crude product, tert-butylamine clavulanate, and polishing to obtain the final product, potassium clavulanate. It is difficult to obtain a high quality product because of the chemical instability of clavulanic acid. Clavulanic acid is degraded rapidly into complexes including multiple components (Parag, Shrikant, Rekha, 2008; Sunderland, Vahdat, 2009). Seven related substances (designated A-G, respectively) have been found in potassium clavulanate as noted in the European Pharmacopoeia. Among these, related substances A, B, C, $\mathrm{D}$ and $\mathrm{F}$ are synthesized by the catabolism of clavulanic acid under acid or alkali conditions (Finn et al., 1984; Haginaka et al., 1985). Related substance $E$ is synthesized by the combination of the amino group of one molecule of clavulanic acid with the carboxyl group of another molecule of clavulanic acid with the opening of the $\beta$-lactam ring (Zhong et al., 2014).

Related substance $G$ is one of the main impurities in commercially available potassium clavulanate, and it directly affects the quality of the final product (Zhong, Cao, Chen, 2008). So far, there has been little relevant research on related substance $\mathrm{G}$ and its mechanism of synthesis. In this study, an impurity in potassium clavulanate with a retention time of 13.5 min was confirmed to be related substance $\mathrm{G}$ by high performance liquid chromatographymass spectrometry/mass spectrometry (HPLC-MS/MS), and the synthetic mechanism of related substance $G$ was investigated. It would be useful to reduce the content of related substance $\mathrm{G}$ to improve the quality of potassium clavulanate.

\section{MATERIAL AND METHODS}

\section{Microbial strains}

The industrial production strain was Streptomyces clavuligerus F613-1.

\section{Reagents}

Ammonium formate, formic acid and methanol were LC grade. Ultra-pure water used for the preparation of running buffers and standard solutions was obtained from a Milli-Q system. All other reagents, such as acetone, isopropyl alcohol, ethanol, acetic acid, sodium hydroxide,
L-tyrosine, succinic acid, sodium alginate and calcium chloride were of analytical reagent grade.

\section{Standard and preparations}

Lithium clavulanate standard, tert-butylamine clavulanate (crude product), potassium clavulanate (final product) and industrial fermentation medium were provided by Lunan Pharmaceutical Co., Ltd. (Shandong, China). The contents of clavulanic acid in the lithium clavulanate standard, tert-butylamine clavulanate and potassium clavulanate were $96.0 \%, 66.5 \%$ and $83.6 \%$, respectively.

\section{Instrumental parameters}

An Agilent 1100 HPLC system and Agilent 12006410 LC-MS/MS were used to determine the content and structure of related substance G. A Mettler AL104 electronic analytical balance were used to weigh the sample. A shaking bed was used in the experiment to determine the synthetic mechanism.

\section{HPLC analysis conditions}

We used the method described in the European Pharmacopoeia (2010) to determine clavulanic acid and related substance $\mathrm{G}$. The content of related substance $\mathrm{G}$ was calculated by the main component self-contrasted method. One milliliter of the test solution was diluted to $100.0 \mathrm{~mL}$ with mobile phase A as the reference solution. The content of related substance $G$ was the ratio of the peak area of related substance $G$ in the test solution to the peak area of clavulanic acid in the reference solution. The HPLC details were as follows: mobile phase A was $0.03 \mathrm{~mol} \mathrm{~L}^{-1}$ ammonium formate solution ( $\mathrm{pH} 4$ ), and mobile phase $\mathrm{B}$ was an equivalent mixture of methanol and mobile phase $\mathrm{A}$. The elution gradient was $0-4 \mathrm{~min}$ mobile phase A 100\%, 4-15 min mobile B 0-50\%, 15-18 min mobile B 50-0\%, 18-30 min mobile A $100 \%$ at a flow rate of $1 \mathrm{~mL} \mathrm{~min}^{-1}$. The temperature inside the column was maintained at $40^{\circ} \mathrm{C}$. Detection was carried out at $230 \mathrm{~nm}$. The injection volume was $20 \mu \mathrm{L}$. Samples were well separated on an Inertsil ODS-3 chromatographic column $(4.6 \mathrm{~mm} \times 150 \mathrm{~mm}, 5 \mu \mathrm{m})$.

\section{HPLC-MS/MS analysis conditions}

HPLC analysis conditions were as described above with post-column split, electrospray ionization, negative ion detection and MS2 scans. The collision energy was $5 \mathrm{~V}$. 


\section{Related substance $G$ analysis during the production of clavulanic acid}

The production process of potassium clavulanate includes three main processes: fermentation, filtration and extraction, and crystallization to obtain the crude product, tert-butylamine clavulanate, and polishing to obtain the final product, potassium clavulanate. We sampled the fermentation broth, crude product and finished product to analyze the stage at which related substance $G$ was generated. We also needed to determine whether related substance $G$ could be generated during the fermentation process. Thus, the blank medium (sterilized) and the fermentation liquids from different time points $(24 \mathrm{~h}$, $48 \mathrm{~h}, 72 \mathrm{~h}$ and $96 \mathrm{~h}$, respectively) during the fermentation process were sampled. All the samples were treated with the following methods according to their characteristics, and the contents of clavulanic acid and related substance $\mathrm{G}$ were determined by HPLC.

Fermentation liquid samples were processed as follows: precisely $5 \mathrm{~g}$ of fermentation liquid was weighed and the sample was diluted to $25 \mathrm{~mL}$ with mobile phase A. The aqueous phase was collected after centrifugation (at a speed of $7100 \mathrm{~g}$ for $4 \mathrm{~min}$ ) and filtered (through a $0.22 \mu \mathrm{m}$ membrane).

The solid samples were processed as follows: precisely $0.25 \mathrm{~g}$ was weighed and diluted to $25 \mathrm{~mL}$ with mobile phase A.

\section{Verification on the biosynthesis precursors of related substance $G$}

The final fermentation broth at $96 \mathrm{~h}$ was chosen as the experimental material. Sterilized shaker flasks with the same fermentation broth were divided into four groups, and then L-tyrosine alone, succinic acid alone, and L-tyrosine and succinic acid together $(1: 1, \mathrm{w} / \mathrm{w})$ were added to three groups to a final concentration of $1 \mathrm{~g} \mathrm{~L}^{-1}$. The fourth group was the control group. All four groups were cultivated on a shaking table at $28^{\circ} \mathrm{C}$ with a rotation speed of $50 \mathrm{rpm}$ for $72 \mathrm{~h}$. Samples at different time points $(0 \mathrm{~h}, 24 \mathrm{~h}, 48 \mathrm{~h}$ and $72 \mathrm{~h}$ ) were analyzed for related substance G.

\section{Study of the biosynthetic mechanism of related substance $G$}

The fermentation broth was centrifuged at $3800 \mathrm{~g}$ for $30 \mathrm{~min}$, and the supernatant was filtered through a 0.22 $\mu \mathrm{m}$ aseptic filter, and the fresh cells were washed with 0.1 $\mathrm{M}$ aseptic Tris-HCl buffer ( $\mathrm{pH} 7.0)$. The supernatant, fresh cells and purified water (as the control) were prepared as follows: samples were mixed with $20 \mathrm{~g} \mathrm{~L}^{-1}$ sterilized sodium alginate solution in a proportion of $1: 1$, and then the mixtures were dropped slowly into $20 \mathrm{~g} \mathrm{~L}^{-1}$ sterilized calcium chloride solution by a sterile syringe. Solid balls then appeared; the balls were washed with $0.1 \mathrm{M}$ aseptic Tris- $\mathrm{HCl}$ buffer ( $\mathrm{pH}$ 7.0) until the washed buffer was colorless. The balls were mixed with $0.1 \mathrm{M}$ aseptic Tris$\mathrm{HCl}$ buffer ( $\mathrm{pH} 7.0$ ), then L-tyrosine and succinic acid were added to achieve a final concentration $1 \mathrm{~g} \mathrm{~L}^{-1}$. The samples were then cultivated with ampicillin $\left(100 \mu \mathrm{g} \mathrm{mL}^{-1}\right)$ on a shaking bed at $28^{\circ} \mathrm{C}$ with a rotation speed $50 \mathrm{rpm}$ for $72 \mathrm{~h}$. Samples at different time points ( 0 h, $24 \mathrm{~h}, 48 \mathrm{~h}$ and $72 \mathrm{~h})$ were analyzed for related substance $\mathrm{G}$.

\section{RESULTS AND DISCUSSION}

\section{Structural identification of the impurity at $13.5 \mathrm{~min}$}

An impurity appears at a retention time of 13.5 $\min$ in some final products of potassium clavulanate. The maximum content of the impurity may reach $0.5 \%(\mathrm{w} / \mathrm{w})$. HPLC analysis showed that the impurity was a single substance and the retention time was similar to that of related substance $\mathrm{G}$, as noted in the section in potassium clavulanate in the European Pharmacopoeia (2010). We speculated that the impurity was related substance G. The chemical structure of related substance G, provided by the European Pharmacopoeia, is shown in Figure 1.

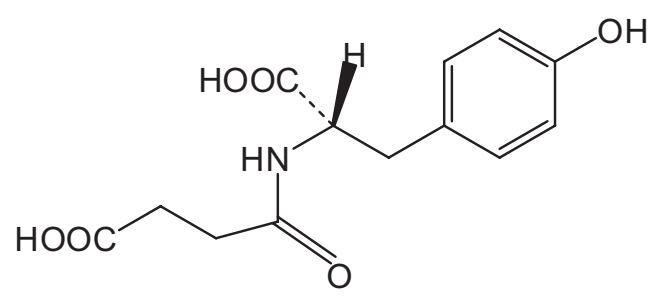

FIGURE 1 - Chemical structure of related substance $G$ from the European Pharmacopoeia (2010).

HPLC is a valid method for the determination of free arginine, glutamine and $\beta$-alanine in nutritional products and dietary supplements (Jeffrey, Paul, 2012). HPLC-MS/ MS is also a method to analyze tebuconazole, tetraconazole enantiomers and plant growth regulators (Ma et al., 2013; Zhang et al., 2012). Tandem mass spectrometry analysis was executed by HPLC-MS/MS in order to define its exact chemical structure. HPLC-MS/MS was used to determine whether the impurity with a retention time of $13.5 \mathrm{~min}$ in the final product (potassium clavulanate) was related substance G. First-order and secondary mass spectrograms 
are shown in Figure $2 \mathrm{a}$ and Figure $2 \mathrm{~b}$, respectively. The results of the mass spectrometry show that the molecular ion mass-to-charge ratio was $\mathrm{m} / \mathrm{z} 280$, and the molecular mass was the same as that of related substance $G$ in European Pharmacopoeia. All these data show that the impurity was related substance $\mathrm{G}$.

(a)

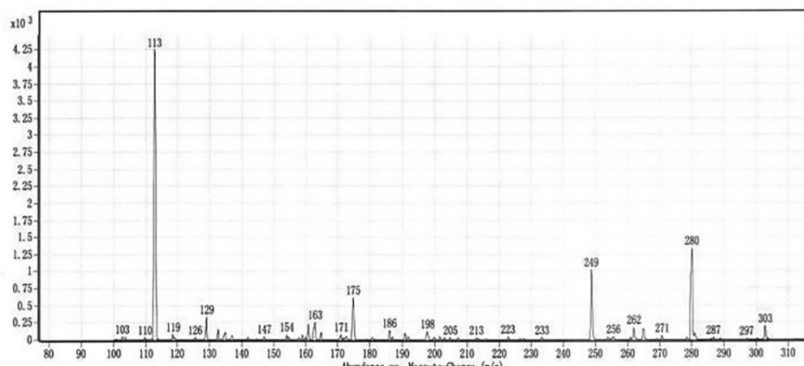

(b)

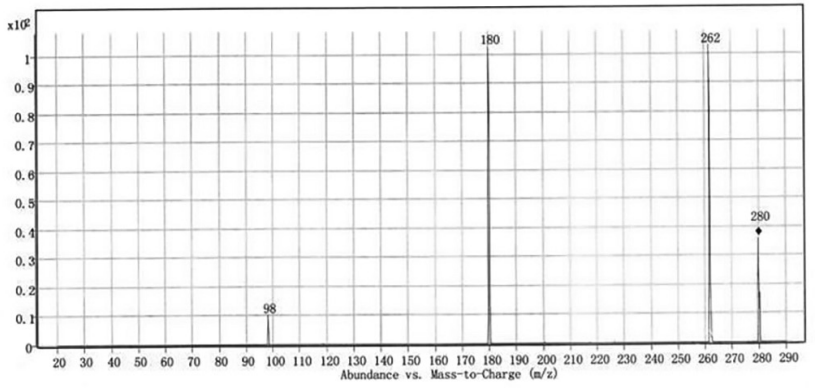

FIGURE 2 - Mass spectra of the substance with a retention time of 13.5 min. (a) First order mass spectrum; (b) Secondary mass spectrum.

Tandem mass spectrometry analysis showed that the molecular ion with $\mathrm{m} / \mathrm{z} 280$ could be dissociated into fragments such as m/z 262, m/z 180 and m/z 98 . Combining the characteristics of fragment ions, relative abundance, the general rule of ion fragmentation, and the chemical structure of related substance $\mathrm{G}$, we speculated on the possible fragmentation path of the molecular ion with $\mathrm{m} / \mathrm{z} 280$ (Figure 3 ).

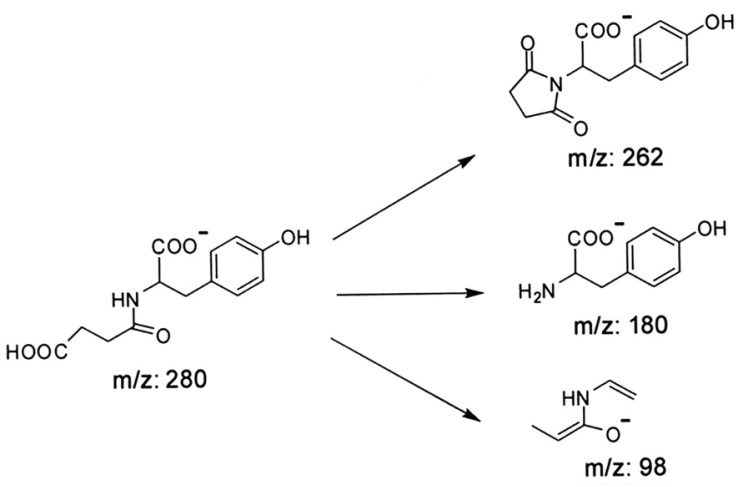

FIGURE 3 - Possible fragmentation path of related substance $G$

\section{Analysis of the producing stage of related substance $G$}

Samples from different production stages were analyzed for clavulanic acid and related substance $\mathrm{G}$ by HPLC, including the blank culture medium, fermentation broth, crude product and the finished product. The results are shown in Figure 4. Neither clavulanic acid nor related substance $\mathrm{G}$ were found in the blank culture medium, while in the final fermentation broth, the relative content of related substance $\mathrm{G}$ to clavulanic acid reached $2.22 \%$. The relative content of related substance $\mathrm{G}$ decreased to $0.17 \%$ and $0.03 \%$ in the crude product and finished product, respectively. Related substance $\mathrm{G}$ was thus generated during fermentation and not in downstream processes.

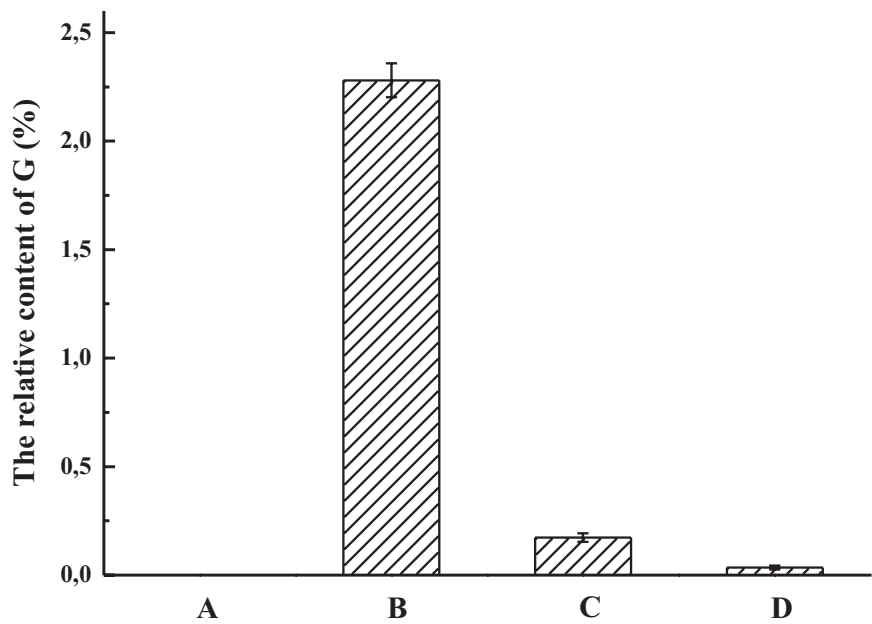

FIGURE 4 - The relative percentage amount of related substance $\mathrm{G}$ during the production process. A: blank culture medium; B: final fermentation broth; C: crude product; D: final product.

The changes in the content of related substance $G$ during the fermentation process were studied in order to analyze the possible synthesis pathway of related substance $\mathrm{G}$. The content of related substance $\mathrm{G}$ at the time points of $0 \mathrm{~h}, 24 \mathrm{~h}, 48 \mathrm{~h}, 72 \mathrm{~h}$ and $96 \mathrm{~h}$ during the fermentation process are shown in Figure 5. There was neither related substance $G$ nor clavulanic acid in the sterilized blank medium. About $0.3 \mathrm{~g} \mathrm{~L}^{-1}$ clavulanic acid was detected at $24 \mathrm{~h}$, and $0.004 \mathrm{~g} \mathrm{~L}^{-1}$ of related substance $\mathrm{G}$ was detected. The concentration of the clavulanic acid reached $2.07 \mathrm{~g} \mathrm{~L}^{-1}$ at $48 \mathrm{~h}$, when related substance $\mathrm{G}$ was $0.026 \mathrm{~g} \mathrm{~L}^{-1}$, so the average biosynthesis rate of related substance $\mathrm{G}$ was $0.0009 \mathrm{~g} \mathrm{~L}^{-1} \cdot \mathrm{h}^{-1}$. Thereafter, clavulanic acid and related substance $\mathrm{G}$ increased simultaneously. At $72 \mathrm{~h}$, related substance $\mathrm{G}$ reached $0.07 \mathrm{~g} \mathrm{~L}^{-1}$, and the average biosynthesis rate increased gradually, up to $0.0018 \mathrm{~g} \mathrm{~L}^{-1} \cdot \mathrm{h}^{-1}$. In the final fermentation broth, clavulanic 
acid reached $4.87 \mathrm{~g} \mathrm{~L}^{-1}$, and related substance $\mathrm{G}$ reached $0.108 \mathrm{~g} \mathrm{~L}^{-1}$, but the average biosynthesis rate of related substance $\mathrm{G}$ decreased slightly to $0.0016 \mathrm{~g} \mathrm{~L}^{-1} \cdot \mathrm{h}^{-1}$. From the results presented here, it can be concluded that related substance $G$ was generated during the middle and later periods of fermentation, and its content increased with fermentation time. However, the average biosynthesis rate decreased slightly during the later period of fermentation.

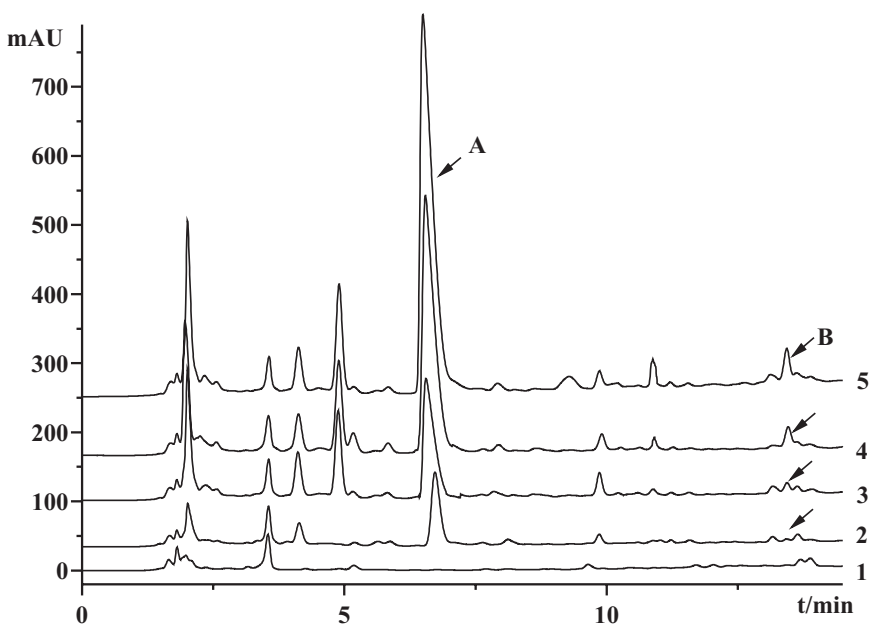

FIGURE 5 - The content of clavulanic acid and related substance G during the fermentation process. A: clavulanic acid, B: related substance G; 1: sterilized blank medium $(0 \mathrm{~h}) ; 2$ : Early stage of fermentation $(24 \mathrm{~h}) ; 3$ : medium stage of fermentation (48 h); 4 : later stage of fermentation $(72 \mathrm{~h})$; 5 : final stage of fermentation (96 h).

\section{Verification of the biosynthesis precursors of related substance $G$}

Related substance $\mathrm{G}$ is called $\mathrm{N}$-succinyltyrosine in EP7.0 (European Pharmacopoeia Commission of the Council of Europe, 2010) and it has been synthesized by chemical methods from L-tyrosine and succinic acid as the raw materials (Chen et al., 2013). However, whether related substance $\mathrm{G}$ is synthesized from L-tyrosine and succinic acid in vivo has not been reported. The final fermentation broth at $96 \mathrm{~h}$ was chosen as the experiment material. L-tyrosine alone, succinic acid alone, and L-tyrosine and succinic acid together $(1: 1, \mathrm{w} / \mathrm{w})$ were added and then cultivated for $72 \mathrm{~h}$, with sampling at $0 \mathrm{~h}$, $24 \mathrm{~h}, 48 \mathrm{~h}$ and $72 \mathrm{~h}$ for the content of related substance G. The data are shown in Figure 6. The content of related substance $\mathrm{G}$ increased in all four groups over time, but the group with L-tyrosine and succinic acid added together had a much higher level than the control group. The content of related substance $\mathrm{G}$ in the control group was $0.111 \mathrm{~g} \mathrm{~L}^{-1}$ at $72 \mathrm{~h}$ and increased by $11.1 \%$. The amount of related substance $\mathrm{G}$ in the group with L-tyrosine alone increased by $12.9 \%$ at $72 \mathrm{~h}$, reaching $0.114 \mathrm{~g} \mathrm{~L}^{-1}$. The amount of related substance $\mathrm{G}$ in the group with succinic acid alone increased by $11.9 \%$ at $72 \mathrm{~h}$, reaching $0.113 \mathrm{~g} \mathrm{~L}^{-1}$. The amount of related substance $\mathrm{G}$ in the group with L-tyrosine and succinic acid together increased by $20.79 \%$ at $72 \mathrm{~h}$, reaching $0.122 \mathrm{~g} \mathrm{~L}^{-1}$; this was significantly higher than the level in the control group.

The content of related substance $G$ increased in the control group because there were some L-tyrosine and succinic acid in the final fermentation broth. Over time, L-tyrosine and succinic acid were consumed, so the biosynthesis of related substance $\mathrm{G}$ slowed gradually and almost stopped in the control group after $48 \mathrm{~h}$. The amount of related substance $G$ increased slightly in the groups with L-tyrosine alone and succinic acid alone, because there were also insufficient precursors. There were sufficient precursors in the group with L-tyrosine and succinic acid added together, so the amount of related substance $\mathrm{G}$ increased and was significantly higher than in the control group at $72 \mathrm{~h}$. From the results presented here, it can be concluded that L-tyrosine and succinic acid are the precursors for the biosynthesis of related substance $\mathrm{G}$ in vivo.

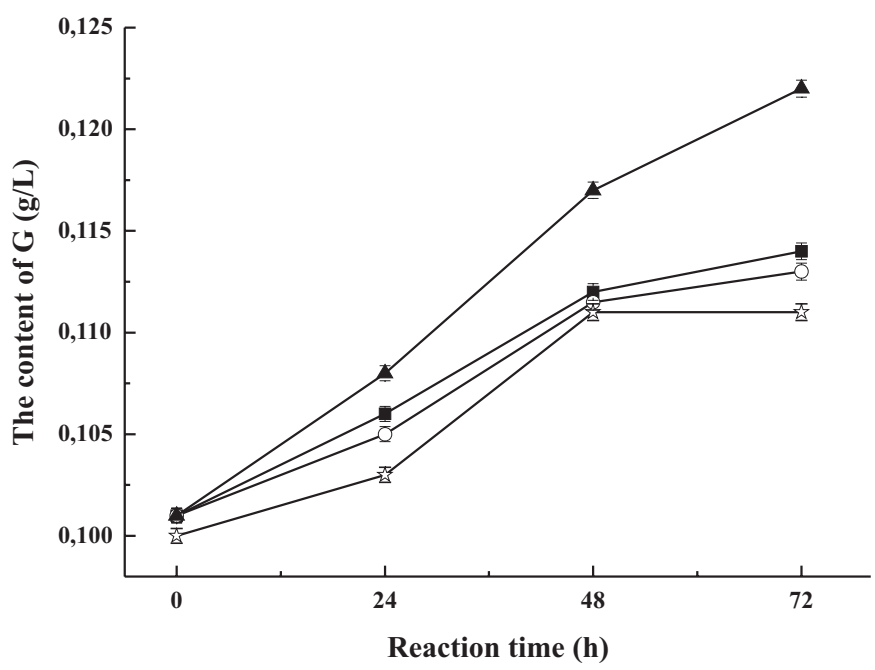

FIGURE 6 - The content of related substance $G$ in the fermentation broth with the addition of different precursors. m: L-tyrosine alone, $\circ$ : succinic acid alone, $\boldsymbol{\Delta}$ : L-tyrosine and succinic acid together, 放: nothing added (control group).

\section{Study of the biosynthetic mechanism of related substance $G$}

Related substance $G$ can be synthesized by chemical synthesis with L-tyrosine and succinic acid as the raw materials (Chen et al., 2013), and can also 
be generated by $S$. clavuligerus, but the synthetic mechanism of related substance $G$ in vivo has not been reported. In this study, we immobilized the supernatant and cells using alginate, and these were cultivated after adding L-tyrosine and succinic acid together as precursors. The content of related substance $\mathrm{G}$ is shown in Figure 7. The data show that related substance G could be detected in the supernatant after immobilization, and the content increased over time, reaching $0.069 \mathrm{~g} \mathrm{~L}^{-1}$ at $72 \mathrm{~h}$. The content of related substance $\mathrm{G}$ in the cells after immobilization was small, and the level in the control group was zero. From these results, extracellular enzymes present in the supernatant may catalyze the biosynthesis of related substance $\mathrm{G}$.

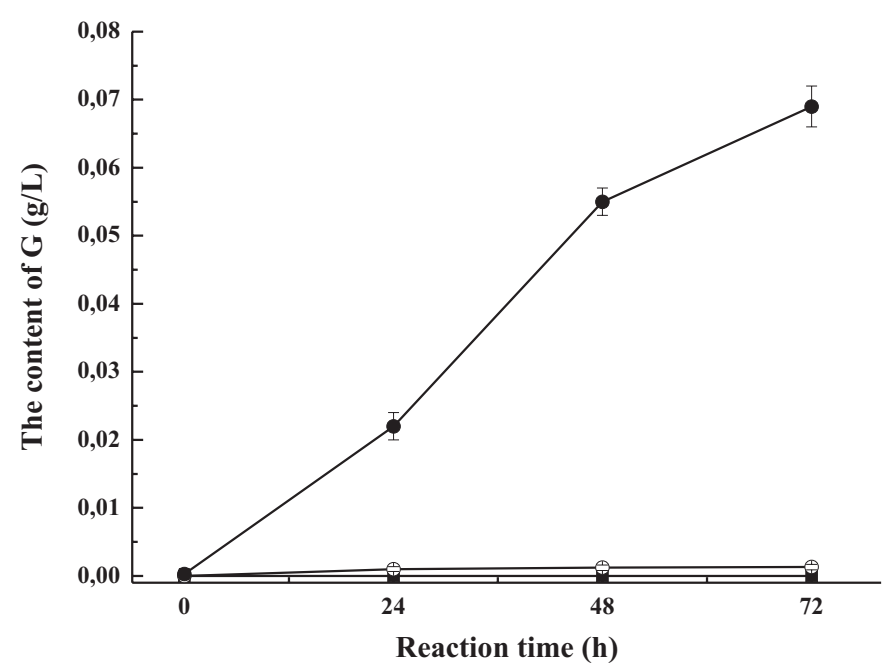

FIGURE 7 - The content of related substance G in supernatant and cell after immobilization by alginate. $\bullet$ : supernatant, $\circ$ : cell, a: control group.

The carboxyl group of succinic acid and the amino group of L-tyrosine form the amide bond in the related substance $\mathrm{G}$ molecule. The biosynthesis is perhaps similar to enzyme-catalyzed amide bond synthesis. First, the carboxyl group of succinic acid is activated by phosphorylation or acylation, and is then attacked by the amino group of L-tyrosine to form the amide bond. The reaction can be catalyzed by specific enzymes such as amide synthetase, or by enzymes for non-peptide amide bond formation (Bordusa, 2000; Maruyama et al., 2012; Ladkau et al., 2011). In addition, proteases as catalysts are capable of accelerating the hydrolysis of peptide bonds in aqueous solution, as well as the synthesis of peptide bonds and non-peptide amide bonds in a small hydrophobic zone (Stepanov, 1996; Chen et al., 2010). So, proteases may be the enzymes required for the biosynthesis of related substance $\mathrm{G}$. The detailed biosynthetic mechanism of related substance $\mathrm{G}$ and the related enzymes are areas of research focus in the future.

\section{CONCLUSIONS}

HPLC-MS/MS analysis verified that the impurity with a retention time of $13.5 \mathrm{~min}$ is related substance $\mathrm{G}$, as noted in European Pharmacopoeia (2010). Related substance $\mathrm{G}$ was formed during fermentation, and increased with fermentation time.

Studies on its synthetic mechanism showed that L-tyrosine and succinic acid were the precursors for the biosynthesis of related substance $\mathrm{G}$ in vivo, and the reaction was deduced to be catalyzed by an enzyme. The enzyme was an extracellular enzyme present in the fermentation supernatant.

\section{ACKNOWLEDGMENTS}

This study was supported by the Shandong Science and Technology Development Project(2014GSF121021).

\section{REFERENCES}

AHARONOWITZ Y.; DEMAIN A.L. Carbon catabolite regulation of cephalosporin production in Streptomyces Clavuligerus. Antimicrob. Agents Chemother., v.14, p.159164, 1978.

BORDUSA, F. Nonconventional amide bond formation catalysis: programming enzyme specificity with substrate mimetics. Braz. J. Med. Biol. Res., v.33, p.469-485, 2000.

CHEN, F.; JIN, X.Q.; CAO, G.X.; ZHANG, X.X.; WANG, S.S.;ZHONG, C.Q. Chemical synthesis and structure identification of the related substance $\mathrm{G}$ in clavulanate potassium. Chin. Chem. Bioeng., v.30, p.84-87, 91, 2013.

CHEN, F.F.; ZHANG, F.K.; WANG, A.M.; LI, H.F.; WANG, Q.Y. Recent progress in the chemo-enzymatic peptide synthesis. Afr. J. Pharm. Pharmacol., v.4, p.721-730, 2010.

EUROPEAN PHARMACOPOEIA COMMISSION OF THE COUNCIL OF EUROPE. Ph. Eur. 7.0, p.2764-2766, 2010.

HAGINAKA, J.; YASUDA, H.; UNO, T.; NAKAGAWA, T. Degradation of clavulanic acid in aqueous alkaline solution: isolation and structural investigation of degradation products. Chem. Pharm. Bull., v.33, p.218-224, 1985. 
JEFFREY, H.B.; PAUL, W. J. Determination of free arginine, glutamine, and $\beta$-alanine in nutritional products and dietary supplements. Food Anal. Methods, v.5, p.821-827, 2012.

LADKAU, N.; HERMANN, I.; BUHLER, B.; SCHMID, A. Enzyme-catalyzed laurolactam synthesis via intramolecular amide bond formation in aqueous solution. Adv. Synth. Catal., v.353, p.2501-2510, 2011.

MA, L.Y.; ZHANG, H. Y.; XU, W. T.; HE, X. Y.; YANG, L. L.; LUO, Y. B.; HUANG, K. L. Simultaneous determination of ${ }^{15}$ plant growth regulators in bean sprout and tomato with liquid chromatography-triple quadrupole tandem mass spectrometry. Food Anal. Methods., v.6, p.941-951, 2013.

FINN, M.J.; HARRIS, M.A.; HUNT, E.; ZOMAYA, I.I. Studies on the hydrolysis of clavulanic acid. J. Chem. Soc. Perkin. Trans. 1, p.1345-1349, 1984.

MARUYAMA, C.; TOYODA, J.; KATO, Y.; IZUMIKAWA, M.; TAKAGI, M.; SHIN-YA, K.; KATANO, H.; UTAGAWA, T.; HAMANO, Y. A Stand-alone adenylation domain forms amide bonds in streptothricin biosynthesis. Nat. Chem. Biol., v.8, p.791-797, 2012.

PARAG S.S., SHRIKANT A.S.; REKHA, S.S. Clavulanic Acid: a review. Biotechnol. Adv., v.26, p.335-351, 2008.

SAUDAGAR, S.P.; SINGHAL, S.R. A statistical approach using $\mathrm{L}_{25}$ orthogonal array method to study fermentative production of clavulanic acid by Streptomyces Clavuligerus MTCC 1142. Appl. Biochem. Biotech., v.136, p.345-359, 2007.
SHETTY, J.; NEETHA, V.M.; PRATAP, K.; ASHA, K. Antibiotic prophylaxis for hysterectomy and cesarean section: amoxicillin-clavulanic acid versus cefazolin. $J$. Obstet. Gynaecol., v.60, p.419-423, 2010.

STEPANOV, V.M. Proteinases as catalysts in peptide synthesis. Pure. Appl. Chem., v.68, p.1335-1339, 1996.

SUNDERLAND, B.; VAHDAT, L. The influence of potassium clavulanate on the rate of amoxicillin sodium degradation in phosphate and acetate buffers in the liquid state. Drug Dev. Ind. Pharm., v.35, p.471-479, 2009.

ZHANG, H.; QIAN, M.R.; WANG, X.Q.; WANG, X.Y.; XU, H.; QI, P.P.; WANG, Q.; WANG, M.H. Analysis of tebuconazole and tetraconazole enantiomers by chiral HPLC-MS/MS and application to measure enantioselective degradation in sStrawberries. Food Anal. Methods, v.5, p.1342-1348, 2012.

ZHONG, C.Q.; CAO, G.X.; CHEN, F. Determination of related substances in clavulanate potassium by HPLC/ESI/MS. Chin. J. Antibiot., v.33, p.750-752, 2008.

ZHONG, C.Q.; CAO, G.X.; JIN, X.Q.; WANG, F.S. Studies on the formation and forming mechanism of the related substance $\mathrm{E}$ in potassium clavulanate production by HPLCMS/MS. Braz. J. Pharm. Sci., v.50, n.2, p.391-399 2014.

Received for publication on $25^{\text {th }}$ January 2014 Accepted for publication on $08^{\text {th }}$ May 2014 
